\title{
Efficiency of systems of heat supply with introduction of automated individual heating substations
}

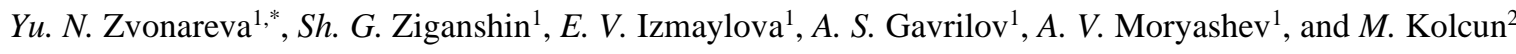 \\ ${ }^{1}$ Kazan State Power Engineering University, Kazan, Russia \\ ${ }^{2}$ Technical University of Kosice, Kosice, Slovakia
}

\begin{abstract}
Article is devoted to increasing efficiency of heat supply systems. We demonstrate research results and an analysis of dependences of overall heat supply system performance indicators at various levels of equipment of consumers with the automated individual heating substations.
\end{abstract}

\section{Introduction}

The system of heat supply is effective if: there is no heat carrier over expenditure and, consequently, there is no over expenditure of electric energy during its transfer; the hydraulic operation mode of district heating networks is stable; the operating and capital expenditures caused as a rule by inefficient functioning of district heating systems (the large number of accidents and damages of main networks caused by violation of a hydraulic operation mode, the overestimated heat carrier expense in a system, etc.) are minimal; normative values of temperature in the heated rooms depending on their purpose are maintained [1].

One of the main actions offered at implementation of programs of increase in power efficiency of the cities is installation of the automated individual heating substations (AIHS) on end user nodes.

However, at upgrade of systems through the installation of AIHS, only economic and power effects affecting the end user (population) are taken into account, and there is no full analysis of influence of these actions on the system of heat supply in general, meaning influence on the consumers who are left without the system of automatic control and on an operation mode of district heating networks and the mode of supplying the heat energy from sources of heat supply are not yet considered [2].

Because of hydraulic communication of all the elements of a system, unsystematic equipment of consumers of AIHS leads to maladjustment of the hydraulic mode of its work. It has a negative impact on reliability of heat supply and reduces overall performance of heat sources and a system in general.

\section{Materials and methods}

During our research, we have obtained the dependences allowing to estimate the required pressure difference at the exit from heat supply source depending on rated pressure difference in nodal points of a system (district heating substation) at introduction of AIHS for the end users [3].

These dependences were received through comparison of the actual values of the operating parameters received on indicators of the installed metering devices in the operating system of heat supply with the results obtained via mathematical modelling of the studied system of heat supply and data obtained as a result of the laboratory experiments.

The dependences of change of key indicators of systems of the centralized heat supply at various percent of installation of AIHS at the end users, namely, the amount of electric energy spent on transfer of the heat carrier and indicators of change of a consumption of conditional fuel on development of thermal energy received as a result of a research are presented in figure 1.

As a result of a research, the optimum percent of consumers equipped with AIHS of the total number of consumers is defined. It is established that if the consumers equipped with AIHS generate less than 30\% or more than $75 \%$ of the total heat load, it does not lead to any significant changes in the operation mode of the heat supply system [4-6].

Equipping consumers generating 30 to $75 \%$ of the total heat load with AIHS leads to hydraulic maladjustments of the entire system that involves a number of problems in heat supply networks of the city: pressure increment in the given pipeline, and as a result, increase in the indicators of an expense of electrical energy demanded on transfer of the heat carrier; the increased values of water temperature in the return pipeline; insufficient heat removal at the consumer.

Nevertheless, there is still economy of fuel due to decrease in a heat load of the consumers equipped with metering devices and regulators (AIHS) [7].

Considering a system of heat supply in general, it is established that the greatest efficiency from implementation of the listed actions is reached when

\footnotetext{
* Corresponding author: skulinaun@mail.ru
} 


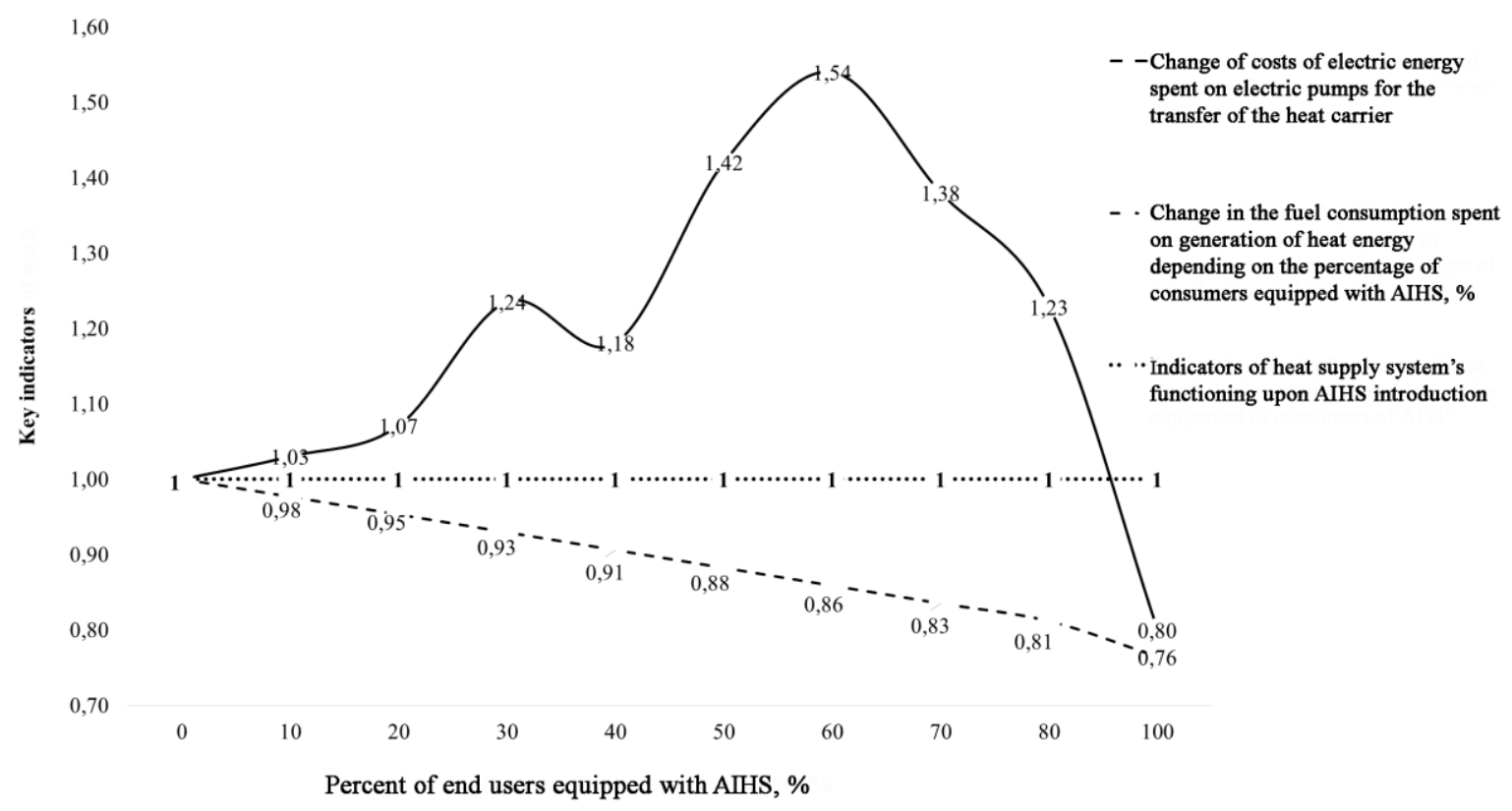

Fig. 1. Dependence of indicators of overall performance of a system of the centralized heat supply on percent of consumers equipped with AIHS.

over $90 \%$ of consumers are equipped with AIHS. There is a decrease in an expense of electrical energy concerning system operation indicators before upgrade and decrease in a consumption of conventional fuel spent on heat generation. When most of the consumers are equipped with AIHS, the hydraulic operation mode of thermal supply grids and the thermal mode in the heated rooms stabilize.

Proceeding from the received dependences, the organizations which are engaged in development of the pre-project documentation for making decision on implementation of actions for implementation of AIHS at the end users, can evaluate weighted average of forecast economy at different percent of equipping consumers with AIHS [8-11] in advance.

The demonstrated research results, calculations, and analysis of experience of the companies, which are engaged in increasing the efficiency of systems of heat supply of the cities and also the analysis of results of optimization of work of the systems of heat supply, which are on balance and service of a number of management companies of the Republic of Tatarstan, state that for each of basic elements of a system of heat supply (source - thermal supply grid - consumer) there is a positive effect when consumers are equipped with AIHS:

1. For a source of thermal energy the effect reached is a decrease in fuel consumption. On the example of Kazan city and on the basis of the document "Scheme and Program of Development of Electro- and Power System of the Republic of Tatarstan" developed and approved by the president of the republic for 2017, when translating all consumers: residential buildings, public places and business properties of the city, powered from the system of the centralized heat supply, on automatic individual weather-dependent heat regulation, economy of fuel spent on heat generation of the city will make up to $23.6 \%$, which as a result may positively affect the tariff setting for the end user [12].

2. For the companies (thermal supply grids) transporting the heat carrier the effect of equipping the end users with AIHS taking into account hydraulic stability of a system of heat supply, consists in decrease in the actual volume of the heat carrier in thermal supply grids, and as a result, reduction of costs of electric energy spent on its transfer. The data obtained as a result of researches predict decrease in an expense of the electric energy on the drive of the electric motor of pumps necessary for transfer of the heat carrier circulating in a heat supply system on average by $20 \%$ if AIHS are installed for all the consumers. These values are based on decrease in a consumption of the network water necessary for providing consumers with standard thermal load. Indicators of change of the required electric energy, for transfer of the heat carrier, can be adjusted taking into account features of each system and the pump equipment (type, the brand of the pump equipment and its efficiency) installed in the thermal supply grids. Decrease in operating and capital expenses for service, construction and reconstruction of district heating networks and district heating stations is should also be taken into account [13].

3. For the end users (residential buildings, public places and business properties) the effect gained after installation of an AIHS consists in achievement of stable indicators of temperatures in the heated rooms and being billed only for the consumed heat. Taking into account that regulation of temperature indoors is carried out according to the temperature schedule and depends on temperature changes of external air directly at the consumer, so-called "underheats" and "overheats" are excluded. Annual indicators of heat consumption 
decrease on average by $28 \%$. This decrease in heat consumption for the end user is reflected in reduction of a payment. As payment for heat consumption is usually the highest component among all the communal servicers, and depending on who pays for the installation of the AIHS (homeowners, or the association of homeowners), the bill can be reduced on average by $45 \%$ [14-15].

Pursuing the economy in each of the elements of a system of the centralized heat supply (source - thermal supply greed-consumer), at systematic and simultaneous introduction of AIHS at the consumers, will allow to raise overall performance of the entire system of the centralized heat supply in borders of the cities and municipal units.

\section{Conclusions}

The received results are directed to increase the effect of energy saving actions and can be used for increase in overall performance of the closed systems of the centralized heat supply powered simultaneously with several sources of thermal energy operating within the borders of a large city.

\section{References}

[1] Y.N. Zvonareva, Y.V. Vankov, Energy saving in systems of heat supply of the large municipal associations powered from several sources of heat Bulletin of the Tomsk Polytechnic University Geo Assets Engineering 326(11), 75-82 (2015)

[2] N.V. Kassina, L.M. Smirnov, Mathematical modeling of branched hydraulic systems Journal of Computer research and modeling 1(2), 173-9 (2009)

[3] N. Voropai, V. Stennikov, S. Senderov, E. Barakhtenko, O. Voitov, A. Ustinov, Modeling of integrated energy supply systems: main principles, model, and applications Journal of Energy Engineering ASCE 143(5), 04017011-1-11 (2017)

[4] S.A. Nazarychev, Yu.V. Vankov, Y.V. Izmailova, Ju.N. Zvonareva, Efficiency of Heating System Phased Introduction of Automatic Control Unit Helix ISSN 2319 - 5592 (Online) (2018)

[5] V.E. Popov, Investments into infrastructure and economic growth: regional aspect Regional economy 1, 59-69 (2009)

[6] I. Postnikov, V. Stennikov, E. Mednikova, A. Penkovskii, Methodology for optimization of component reliability of heat supply systems Journal of Applied Energy 227, 365-74 (2018)

[7] Y.N. Zvonareva, Y.V. Vankov, E.M. Onuchin, Modelling of the thermal network operational mode directed at increase of its power efficiency International Conference on Industrial Engineering, Applications and Manufacturing (ICIEAM) St. Petersburg 1-3 (2017)

[8] A.G. Batychin, A.V. Kalygin, Modeling of modern systems of the centralized heat supply the Bulletin of the Irkutsk state technical university $\mathbf{8 ( 5 5 )}$, 84-91 (2011)
[9] S. Putz, P. Reiter, R. Söll, Smart Heat Supply in Austria within the PITAGORAS Project Journal of Energy Procedia 91, 573-7 (2016)

[10] I.S. Shein, A.V. Izvekov, Collaboration of two sources of heat supply Reliability and safety of power 2(17), 55-60 (2012)

[11] Yu.N. Zvonareva, Yu.V. Vankov, S.A. Nazarychev, Estimation of economic effect for consumers in terms of adoption of automatic junctions of acquisition of heat energy Journal of Inzhenernyj vestnik Dona 4 URL: iv don.ru/ru/magazine/archive/n4y2015/3315 (2015)

[12] L.O. Dikul, Priority directions of venture investment activity in industrial sector of economy Journal of Economy, statistics and informatics 4, 30-35 (2011)

[13] M.F. Drigo, Methodology of an assessment of economic efficiency investment decisions Management in Russia and abroad 1, 18-24 (2008)

[14] T.A. Rafalskaya, Investigation of failures in operation of heat networks of large heat supply systems Thermal Engineering 64(4), 313-7 (2017)

[15] Yu.N. Zvonareva, Yu.V. Vankov, Work of system of heat supply at stage-by-stage introduction of the automated individual thermal points News of higher educational institutions. Problems power engineering specialists 19(1-2), 30-41 (2017) 